\title{
GENETIC POLYMORPHISM OF PROPERDIN FACTOR B (BF) IN A CHINESE POPULATION: EXISTENCE OF TWO RARE VARIANTS
}

\author{
Zhijung Luo, Chuanshu Du, ${ }^{1}$ Katsushi Tokunaga, \\ and Keiichi OMOTO ${ }^{2}$ \\ ${ }^{1}$ Department of Medical Genetics, Sun Yat-sen University \\ of Medical Sciences, Guangzhou, China \\ ${ }^{2}$ Department of Anthropology, Faculty of Science, \\ The University of Tokyo, Tokyo 113, Japan
}

\begin{abstract}
Summary Genetic polymorphism of properdin factor B (BF) was investigated in sera from 259 healthy individuals living in Guangzhou, southern China, by means of high voltage agarose gel electrophoresis followed by immunofixation. Besides the common phenotypes, SS, FS, FF and SS07, two rare heterozygous phenotypes tentatively named as SSG1 and SFG2 were observed. The allele frequencies estimated for $B F^{*} S, B F^{*} F, B F^{*} S 07$, $B F^{*} S G 1$ and $B F^{*} F G 2$ were $0.8668,0.1197,0.0077,0.0019$ and 0.0039 , respectively. Family data indicated an autosomal, codominant inheritance for the $B F^{*} F G 2$ allele.
\end{abstract}

\section{INTRODUCTION}

Properdin factor B (BF) is a proactivator in the alternative pathway of complement activation. Genetic polymorphism of human BF was first described by Alper et al. (1972). The interest in the BF polymorphism has been increased since the BF locus was reported to be linked to the HLA loci on chromosome 6 (Allen, 1974; Rittner et al., 1975; Olaisen et al., 1975). At least $20 \mathrm{BF}$ allotypes have been described so far (Mauff et al., 1978; Larsen et al., 1981; Davrinche et al., 1982; Tokunaga et al., 1982; Dykes et al., 1981, 1983). Considerable geographical differences were noted in the distribution of BF allotypes.

In the mainland Chinese populations, there was only a single report of BF polymorphism (Zhao, 1983). It dealt with a population from Shanghai, east-central China, and described the frequences for three common alleles, $B F^{*} F, B F^{*} S$ and $B F^{*} S 07$. Recently, we examined the BF types among patients of diabetes mellitus in Guangzhou, southern China (Luo et al., 1986). In this paper, we describe the detailed data on the BF polymorphism in healthy adults living in Guangzhou city.

Received November 21, 1986; Accepted January 21, 1987 


\section{MATERIALS AND METHODS}

Blood samples were obtained from 259 unrelated healthy adults living in Guangzhou city who attended routine antenatal clinic for genetic counselling at the First Affiliated Hospital of Sun Yat-sen University of Medical Sciences. Specimens for family study were obtained from a family of a propositus showing a rare BF variant. BF typing was carried out by means of a high voltage agarose gel electrophoresis and subsequent immunofixation according to Alper et al. (1972), with slight modifications (Tokunaga et al., 1982).

\section{RESULTS AND DISCUSSION}

The results of BF typing in the present study are shown in Table 1. In agreement with the result of Zhao (1983) on east-central China, the present study showed the occurrence of three common $\mathrm{BF}$ alleles, $B F^{*} S, B F^{*} F$ and $B F^{*} S 07$, and the absence of $B F^{*} F 1$.

Table 2 lists the frequencies of the common BF alleles in various populations thus far reported. The frequency of $B F^{*} S$ is higher than that of $B F^{*} F$ in the present study, corresponding to the other reports on Mongoloid and Caucasoid populations. The distribution of BF allele frequencies in Guangzhou population was found to be similar to that in the populations from east-central China, and probably also from Thailand and in Lapps, but considerably different from those in Japanese and Koreans. These latter populations appears to have slightly higher frequencies for $B F^{*} F$ than in Chinese populations, and lack $B F^{*} S 07$. Marked deviation in the gene frequency distribution is notable between Asian and African populations.

Besides the common BF phenotypes, two unusual types were identified, each of which was considered to be heterozygous for a rare variant BF allele (Fig. 1). One of these denoted as type SSG1 was found in a single individual, and showed a BF

Table 1. Distribution of phenotypes and allele frequencies of BF in southern Chinese.

\begin{tabular}{lrrrrr}
\hline Phenotypes & N. Obs. $(\%)$ & N. Ex. $\%$. & \multicolumn{2}{c}{ Allele frequency } \\
\cline { 1 - 3 } SS & $197(76.06)$ & $194.60(75.14)$ & $B F^{*} S:$ & $0.8668 \pm 0.0149$ \\
FS & $48(18.53)$ & $53.75(20.75)$ & $B F^{*} F:$ & $0.1197 \pm 0.0143$ \\
FF & $7(2.70)$ & $3.71(1.43)$ & $B F^{*} S 07: 0.0077 \pm 0.0035$ \\
SS07 & $4(1.50)$ & $3.46(1.34)$ & $B F^{*} S G 1: 0.0019 \pm 0.0017$ \\
SSG1 & $1(0.39)$ & $0.85(0.33)$ & $B F^{*} F G 2: 0.0039 \pm 0.0025$ \\
SFG2 & $2(0.77)$ & $1.75(0.68)$ & & \\
Total & $259(100.00)$ & $258.12(99.66)$ & & 1.0000 \\
\hline
\end{tabular}

$\chi^{2}=2.476,1$ d.f., $\quad \mathrm{p}>0.10$. 
Table 2. Comparison of BF allele frequencies in different populations.

\begin{tabular}{|c|c|c|c|c|c|c|c|}
\hline \multirow{2}{*}{ Population } & \multirow{2}{*}{ N.ex. } & \multicolumn{4}{|c|}{ BF allele frequency } & \multirow{2}{*}{$P$} & \multirow{2}{*}{ Authors } \\
\hline & & $S$ & $F$ & $F 1$ & $S 07$ & & \\
\hline S. Chinese & 259 & .867 & .120 & 0 & .008 & - & This study \\
\hline E. Chinese & 200 & .870 & .127 & 0 & .003 & ns & (1) \\
\hline Thai & 184 & .902 & .098 & 0 & 0 & $\mathrm{~ns}$ & (2) \\
\hline Korean & 220 & .775 & .225 & 0 & 0 & $* *$ & (3) \\
\hline Japanese & 487 & .801 & .198 & 0 & 0 & ** & (4) \\
\hline Saudi Arabian & 246 & .474 & .447 & .020 & .059 & ** & (5) \\
\hline North African (Negroid) & 944 & .282 & .655 & .034 & .025 & $* *$ & (6) \\
\hline Cameroon & 275 & .373 & .595 & .029 & .003 & ** & $(5)$ \\
\hline Tunisian & 375 & .617 & .281 & .019 & .083 & $* *$ & (7) \\
\hline Mali & 457 & .300 & .640 & .046 & .014 & ** & $(7)$ \\
\hline Spaniard & 330 & .658 & .266 & .052 & .022 & ** & (8) \\
\hline French (Basque) & 201 & .550 & .296 & .139 & .015 & $* *$ & (9) \\
\hline Dane & 318 & .780 & .203 & .008 & .009 & $* *$ & (10) \\
\hline West German & 1,245 & .808 & .174 & .008 & .009 & $*$ & $(6)$ \\
\hline Norwegian & 300 & .817 & .172 & .005 & .007 & * & (11) \\
\hline Lapp (Norway) & 197 & .888 & .112 & 0 & 0 & ns & (11) \\
\hline North American (Caucasoid) & 158 & .709 & .278 & 0 & .013 & $* *$ & $(12)$ \\
\hline North American (Negroid) & 127 & .437 & .512 & .051 & 0 & $* *$ & (12) \\
\hline
\end{tabular}

$P$ denotes the probability for a chi-square heterogeneity test between data of this study and those of other reports: ns, not significant, * significant at $1 \%$ level, ** significant at $0.1 \%$ level. Authors: (1) Zhao, 1983, (2) Greiner et al., 1980, (3) Park et al., 1985, (4) Tokunaga et al., 1982, (5) Goedde et al., 1979a, 1979b; (6) Mauff et al., 1975; (7) Davrinche et al., 1981; (8) Rodriguez-Córdoba et al., 1981; (9) Ohayon et al., 1980; (10) Mortensen and Lamm, 1981; (11) Teisberg and Olaisen, 1977; (12) Alper et al., 1972.

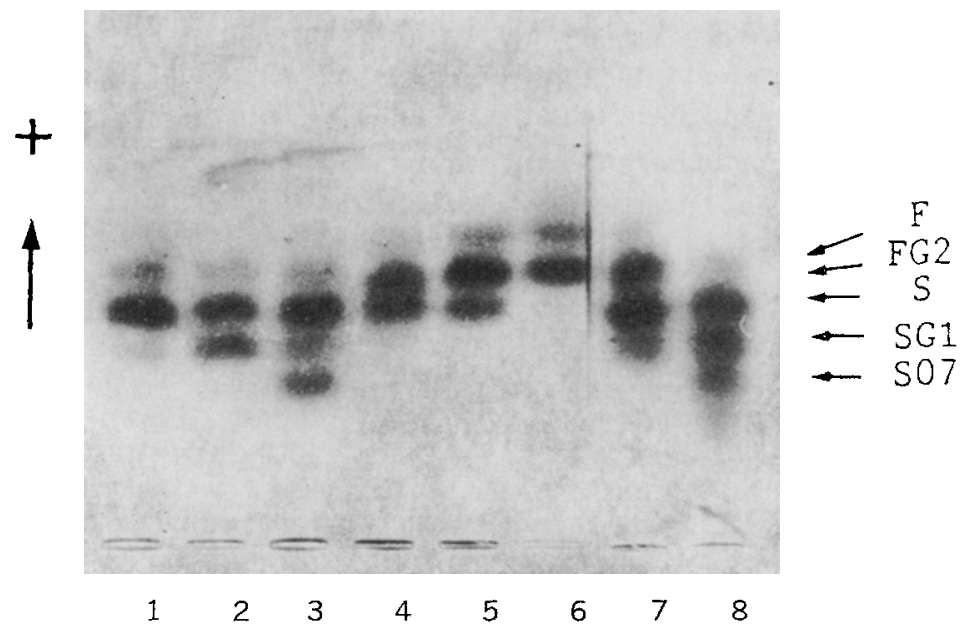

Fig. 1. Photograph of BF phenotypes observed in southern Chinese. 1, SS; 2, SSG1; 3, SS07; 4, SFG2; 5, FS; 6, FF; 7, FS+SSG1 (mixture); 8, SS07+SSG1 (mixture). 


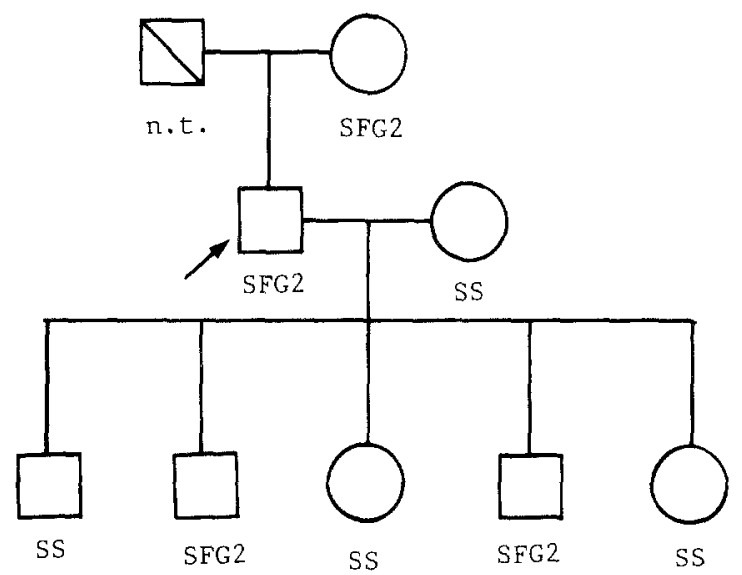

Fig. 2. A pedigree suggesting the autosomal, codominant inheritance of $B F^{*} F G 2$. n.t., not tested. The arrow indicates the propositus.

band intermediate between S and S07 corresponding the position of the cathodal minor band of type SS. When the plasma was mixed with those of types FS and SS07, respectively, three-band patterns emerged (Fig. 1, lane 7 and 8). The relative mobility of this variant was estimated to be within the range of $0.35-0.40$, not greater than 0.45 . No family study could be carried out for this variant. The variant allele was tentatively called $B F^{*} S G$ ( (S Guangzhou 1).

The another variant type SFG2 was encountered twice in the unrelated subjects. The variant band had mobility slightly slower than that of BF F in our electrophoretic system (Fig. 1, lane 4). It is similar to, but considered to be slightly different from, BF F03 described by Dykes et al. (1983). It was possible for one of the propositi to carry out family study. As shown in Fig. 2, four members were found to carry the variant allele tentatively called $B F^{*} F G 2$ (F Guangzhou 2), indicating autosomal, codominant inheritance.

To our knowledge, at least $16 \mathrm{BF}$ variants have been described besides the polymorphic allotypes, S, F, F1 and S07. Majority of these rare variants have been found in Caucasoid or Negroid populations. As for Mongoloid populations, a single rare variant, BF FT(F075) has been reported in Japanese (Tokunaga et al., 1981, 1982). Recently, another variant, BF S065, was reported from Japanese, but the details of this variant were not known (Miyano et al., 1986). In the present study, two further rare variants are added to the list of known BF variants in Mongoloid populations.

\section{REFERENCES}

Allen, F.H., Jr. 1974. Linkage of HL-A and GBG. Vox Sang. 27: 382-384.

Alper, C.A., Boenisch, T., and Watson, L. 1972. Genetic polymorphism in human glycine-rich beta-glycoprotein. J. Exp. Med. 135: 68-80. 
Davrinche, C., Rivat, C., Rivat-Peran, L., Helal, A.N., Boukef, K., Lefranc, M.P., and Lefranc, G. 1981. Genetic variants of C3 and properdin factor B in a population from Tunisia. Hum. Hered. 31 : 299-301.

Davrinche, C., Ravit, C., Ravit-Peran, L., Cazes, M.H., and Chaventer, A. 1982. A new fast variant $\left(B F^{*} 08\right)$ of the $\mathrm{BF}$ polymorphism. J. Immunogenet. 9: 367-370.

Dykes, D.D., Polesky, H.F., and Crawford, M.H. 1981. Properdin factor B (BF) distribution in North and Central American populations. Electrophoresis 2: 320-323.

Dykes, D.D., DeFurio, C.M., and Polesky, H.F. 1983. Five new rare variants of the properdin factor B (BF) locus. Am. J. Hum. Genet. 35: 652-655.

Goedde, H.W., Benkmann, H.G., Agarwal, D.P., Hirth, L., Bienzle, U., Dietrich, M., Hoppe, H.H., Orlowski, J., Kohne, E., and Kleihauer, E. 1979a. Genetic studies in Saudi-Arabia: Red cell enzyme, haemoglobin and serum protein polymorphism. Am. J. Phys. Anthropol. 50: 271-278.

Goedde, H.W., Benkmann, H.G., Agarwal, D.P., Bienzle, U., Guggenmoos, R., Rosenkaimer, F., Hoppe, H.H., and Brinkmann, B. 1979b. Genetic studies in Cameroon: Red cell enzyme and serum protein polymorphisms. Z. Morph. Anthropol. 70: 33-40.

Greiner, J., Weber, F.J., Mauff, G., and Baur, M. 1980. Genetic polymorphism of properdin factor $\mathrm{B}(\mathrm{BF})$, the second component (C2), and the fourth component (C4) of complement in leprosy patients and healthy controls from Thailand. Immunobiology 158: 134-138.

Larsen, B., Salimonu, L.S., Cow, C., and Marshal, W.H. 1981. Bf polymorphism. A very fast variant from Nigeria. Hum. Genet. 56: 395-396.

Luo, Z., Du, C., Yu, B., Liang, Y., Tokunaga, K., and Omoto, K. 1986. Genetic polymorphism of properdin factor B (BF) in Chinese patients with two types of diabetes mellitus. Jpn. J. Human Genet. 31 : 259-262.

Mauff, G., Hummel, K., and Pulverer, G. 1975. Properdin factor B (glycine-rich beta-glycoprotein or $\mathrm{C} 3$ proactivator)-polymorphism: Genetic and biochemical aspects. First application to paternity cases. Z. Immun-Forsch. 150:327-338.

Nauff, G., Gauchel, F.D., and Hitzeroth, H.W., 1976. Polymorphism of properdin factor B in South African Negroid, Indian and Colored populations. Hum. Genet. 33: 319-322.

Mauff, G., Hauptmann, G., Hitzeroth, H.W., Gauchel, F., and Scherz, R. 1978. The nomenclature of properdin factor B allotypes. Z. Immun-Forsch. 154: 115-120.

Miyano, M., Nanjo, K., Okai, K., Sowa, R., Nomura, Y., Kondo, M., Sanke, T., Kawa, A., Miyamura, K., Aiyathurai, E., Ferunando, R., and Vichayanrat, A. 1986. Properdin factor B frequencies in four Asian populations. Hum. Hered. 36: 129-131.

Mortensen, J.P. and Lamm, L.U. 1981. Quantitive differences between complement factor-B phenotypes. Immunology 42: 505-511.

Ohayon, E., De Mouzon, A., Hauptmann, G., Klein, J., Abbal, M., Constans, J., Mayer, S., and Ducos, J. 1980. High frequency of the properdin factor Bf F1 and its linkage to HLA in French Basques. J. Immunogenet. 7: 441-445.

Olaisen, B., Teisberg, P., Gedde-Dahl, T., Jr., and Thorsby, E. 1975. The Bf locus in the HLA region of chromosome 6: Linkage and association studies. Humangenetik 30: 291-296.

Park, K.S., Tokunaga, K., and Omoto, K. 1985. Genetic polymorphism of human complements $\mathrm{BF}$ and $\mathrm{C} 2$ in Korean: Population and association studies. Jpn. J. Human Genet. 30: 9-14.

Rittner, C., Grosse-Wilde, H., Rittner, B., Scholz, S., Lorenz, H., and Albert, E.D. 1975. Linkage group HLA-MLC-BF (properdin factor B): The site of the Bf locus at the immunogenetic group on chromosome 6. Humangenetik 27: 173-183.

Rodriguez-Córdaba, S., Bootello, A., and Arnaiz-Villena, A. 1981. BF polymorphism and its relationship with HLA antigens in a sample of the Spanish population: High BF F1 frequencies. Tissue Antigens 17: 231-237.

Teisberg, P. and Olaisen, B. 1977. Properdin factor B (BF) in Norway. Vox Sang. 32: 52-55. 
Tokunaga, K., Omoto, K., Maeda, H., Juji, T., Ishiba, S., and Maruyama, H. 1981. Bf and C2 polymorphism in Japanese patients with juvenile-onset diabetes mellitus: Existence of a variant Bf allele. Tissue Antigens 18: 365-368.

Tokunaga, K., Araki, C., and Omoto, K. 1982. Polymorphism of properdin factor B in Japanese. Description of a rare variant and a data of association with HLA and C2, Hum. Genet. 60: $42-45$.

Zhao, Tongmao. 1983. Genetic polymorphisms of $\mathrm{C} 3$ and $\mathrm{Bf}$ in the Chinese population. Hum. Hered. 33: 36-38. 